\title{
Accessibility to spinal cord injury care worldwide: the need for poverty reduction
}

\author{
E Weerts ${ }^{1}$ and JJ Wyndaele ${ }^{2}$ \\ ${ }^{1}$ Technical Advisor SCI Project - Vietnam, Handicap International Belgium and ${ }^{2}$ Antwerp University Hospital, Antwerp, Belgium \\ E-mail: spinalcord@uza.be
}

Dear Spinal Cord Reader,

To suffer a spinal cord lesion means not only an enormous change in an individual's life, but also in the lives of those around the individual. The burden is huge, but can vary widely from person to person, and from country to country. In this editorial you can read a message from Eric Weerts, someone who has been worked for many years in areas where comprehensive care has had to be started from scratch. It reminds us that our care must be wide and fundamental, in order to create in a society a place which permits not only proper acute management but lifelong, realistic support.

'Since our Egyptian ancestors described the condition of spinal cord injury (SCI), for treatment or or not, SCI care has been through tremendous developments that have contributed to making living with SCI more meaningful. The attention given to SCI incidence during the last century's world wars laid the foundations for the modern management of SCI, accompanied by the social and economic development of the western world. But economic opportunities for persons with SCI are not evenly spread in the world and this certainly has an impact on the way SCI care is provided, its quality and whether or not individuals have the opportunity to benefit from it. The benefits and speed at which research has been proceeding in the western world has not yet trickled down to the poorer nations of the world in general. There are still evident gaps in access to and quality of care between countries such as Haiti, and USA and Canada, for instance. Within the borders of certain countries, discrepancies also exist between urban and rural areas, as in countries such as India, China and Vietnam. It is a challenge to evenly spread know-how and to enhance the exchange of information in order to maximize the benefits for people living with SCI. In Vietnam, Handicap International Belgium has been supporting, since 2003, the set up of seven SCI units with the Vietnamese Ministry of Health. A significant number of traumatic SCIs result from labor accidents in the sector of seasonal construction work, and these individuals face a huge challenge to overcome their SCI and rebuild their lives to enable them to participate in society or to try and reduce the burden as much as they can on their family and community. The insufficient systems for coping financially after these accidents, systems which ideally should support them, create a strong risk of producing poverty and economic hardship. SCI professionals make big efforts to help persons with SCI to adjust after onset. But an equivalent effort is also needed to keep the individuals out of a life of poverty and hardship after rehabilitation, especially if such individuals are the main income earners, as in most cases in Vietnam. Advances in research and strategies to increase economic and social participation for SCI individuals need to be reinforced on the one hand (as a cure for SCI is not available yet), but most importantly the epidemiological data that countries such as Vietnam are trying to gather can help define the profile of individuals who are most at risk, physically and economically, of being impoverished after an SCI accident. Only a long term comprehensive approach to SCI care and accompanying prevention programs can help to prevent this vicious cycle of poverty and SCI in the future.'

You will find a large number of interesting manuscripts in this issue dealing with different important aspects of SCI care, including employment, sexuality and many more. Enjoy exploring them.

Spinal Cord (2011) 49, 767; doi:10.1038/sc.2011.73 